\section{Richard of York's battles not in vain}

\section{Ann Henderson-Sellers}

Rainbows, Halos, and Glories. By Robert Greenler. Pp.240. ISBN 0-521-23605-3. (Cambridge University Press: 1981.) £15, $\$ 24.95$.

ACCURATE recollection of the ordered colours of the rainbow by means of the nursery sentence, "Richard Of York Gave Battle In Vain", is a necessary but insufficient basis for understanding in the eyes of Robert Greenler. He wants us also to be moved to wonder at the mysteries of optical phenomena in the sky. His book is reminiscent of a fascinating, extended tutorial with a professor of physics who, fortunately, combines hard scientific research with an almost childlike delight in beautiful things. During his discourse we are prompted to exclaim at magnificence, explain apparent enigmas and reinterpret historical events through computer simulations of atmospheric optics.

The book divides into three sections dealing with rainbows and ice-crystal optics, and then simulation and understanding of historical and modern sky displays, before finally returning to colourful mysteries, myths and mirages. Throughout, facts and frustrations are, like the individual rainbow we each view, enriched by Greenler's personal ex periences. For instance, he illustrates the concept of the constant angular size of rainbows by a description of his doomed attempts to photograph the, apparently, miniature bow formed in the spray of his garden hose. The author is clearly "hooked" on his subject; he admits to seeing and searching for rainbows everywhere and has even captured infrared bows on film.

Despite his obvious love of rainbows it is with the optical displays formed by icecrystals that Greenler is most strongly associated. As a physicist who has spent extended periods in Antarctica and the Arctic his fascination with this topic is understandable, but it is frustrating to realize that many of the sky effects he illustrates in this section are seen only rarely in more populated regions. This is because the huge variety of optical effects discussed depend upon the presence of simple hexagonal ice-crystals while most of us see our ice-crystals as snowflakes. This pinpoints the only real criticism that I can make of the book: it is not focused on a specitic readership. As a meteorologist I am frustrated by the fact that the weather which, after all, is creating most of these effects, is mostly ignored. This is a pity because it makes an otherwise outstanding book tricky to use directly in taught courses. Despite the fact that the book is not intended as a textbook, with little additional effort topics could have been related to other disciplines. For instance, the very thin cirrostratus clouds responsible for the $22^{\circ}$ halo, itself generally considered as a forerunner of stormy weather, could also be considered to be a sky phenomenon. I can testify to having used halo occurrence to convince a nonmeteorologist that a blue sky could be totally cloud-covered. Despite these reservations I was drawn on by the enthusiasm of the writing. Indeed, I spent some time testing the author's assertion that hexagonal ice-crystals have preferred orientations in the atmosphere, to the extent of spinning and dropping computer cards around my office.

With a flair for detective work which Holmes would have envied, Greenler considers his computer simulation of the famous "Arcs of Lowitz"'. These composed part of the historic sky display seen and sketched by Tobias Lowitz in St Petersburg in 1790. The accuracy of the simulated curves seems remarkable but Greenler remained dissatisfied. By returning to the written description he has demonstrated that the sketch is not a "snapshot" but a composition of a number of hours of viewing. This revelation solves the outstanding problems

\section{Evidence of intent}

\section{John Stachel}

The Greatest Power on Earth: The Story of Nuclear Fission. By Ronald W. Clark. Pp.342. ISBN 0-283-98715-4. (Sidgwick \& Jackson: 1980.) $£ 8.95$. To be published in the USA by Harper \& Row, $\$ 13.95$.

SHORTLy after the accident at Three Mile Island, a Japanese journalist visited a centre for evacuees from the vicinity of the reactor. As startling as the accident itself was the fact that a reference to Hiroshima drew a blank from those he interviewed; none of them recognized the name. Such ignorance in itself justifies more books on the story of the atomic bomb, which is basically the topic of Clark's book.

Over two-thirds is devoted to the story, from the discovery of atomic fission in late 1938, through the wartime efforts to develop nuclear weapons in Britain, the United States, Germany and Russia, up to the explosion of the first Russian bomb in 1949. A 40-page prologue to the book attempts a potted history of nuclear physics; while the last 40 pages wind up the story with brief accounts of the development of the fusion or hydrogen bomb, the attempts to use fission as an energy source and the growing awareness of radiation perils associated with peaceful and military uses of nuclear power.

The prologue is not too successful. It betrays a shaky acquaintance with the which depended upon knowledge of the solar zenith angle.

The final 50 pages are devoted to colourful optical phenomena in both senses of the word. We are treated to pictures, and explanations, of white and black clouds in the same scene and then yellow, green, blue and red clouds. Such comparatively "every-day" sights pale before the "Specter of the Brocken". This apparition takes the form of a misty giant around whose head are a series of brilliant halos. Many air travellers have seen the same effect, a glory, which simply requires the observer to be in direct sunlight with his anti-solar point projected onto a cloud.

In the opening pages of the book the author states, "I have chosen, knowingly to include myself . . . my delight at seeing ... my excitement in the process of discovery". Despite my slight unease at such an apparently selfish exercise I shall use and recommend the text. Like the Pied Piper of Hamlin in his rainbow-coloured coat, Greenler charmed me into following and will, I am sure, similarly entrap other readers. It appears that the white rose of the house of York was not lost in vain.

Ann Henderson-Sellers is a Lecturer in Meteorology at the University of Liverpool, currently studying global climate at the Goddard Institute for Space Studies, New York.

scientific literature, resulting in numerous small errors and confusions. The placement of emphasis, too, is sometimes curious.

The core of the book demonstrates a wide acquaintance with the atomic bomb literature, both original documents (including some discussed in print for the first time) and later memoirs and analyses. On the whole, it seems a thorough and reliable account, correctly giving greater emphasis to work done in Britain than many American sources. This portion of the book commends itself to those in search of a readable, fairly non-technical account of the scientific, diplomatic and military events leading up to the "Birth of the Bomb" (to use the title of Clark's previous account of Britain's underrated contribution to the early phases of the story). Those in search of a deeper analysis of the potential background to the decision to drop the two bombs on Japan are still advised to consult Martin Sherwin's $A$ World Destroyed (Knopf, 1975).

The frequent use of hyperbole is annoying: "In 1905 Einstein erupted into a surprised world" (elsewhere "an astounded scientific world" receives Einstein's 1905 relativity paper); Russian nuclear research is interrupted in 1941 because "German tanks with muffled treads moved through the darkness across the Russian frontier", and so on. There are also a few curious phrases: "The predominance of Jewish nuclear physicists on the Continent - in strong contrast to the situation in Britain - 